2014-07

\title{
Public perceptions of sharks: Gathering support for shark conservation
}

\author{
Friedrich, LA
}

http://hdl.handle.net/10026.1/9056

10.1016/j.marpol.2014.02.003

Marine Policy

Elsevier BV

All content in PEARL is protected by copyright law. Author manuscripts are made available in accordance with publisher policies. Please cite only the published version using the details provided on the item record or document. In the absence of an open licence (e.g. Creative Commons), permissions for further reuse of content should be sought from the publisher or author. 


\title{
Public perceptions of sharks: gathering support for shark conservation
}

\section{Laura A. Friedrich, Rebecca Jefferson, Gillian Glegg}

Centre for Marine and Coastal Policy Research, Marine Institute, Plymouth University, Reynolds Building, Drake Circus, Plymouth PL4 8AA, UK

\begin{abstract}
With increasing evidence of the destructive impacts of human activities on the ocean there is a growing call for stronger public engagement in marine governance. An understanding of marine issues and pro-environmental values are key elements that influence an individual's engagement in conservation and pro-environmental behaviour. This paper presents a study on public perceptions of sharks and shark conservation in the UK. The study investigated knowledge of and attitudes towards sharks of a group of individuals with a clear interest in the marine environment, as well as possible factors that might influence their perceptions of sharks, in order to make recommendations on how to foster engagement in shark conservation. The key finding was that important prerequisites for engagement in shark conservation exist among parts of the UK public. However, this does not seem to be enough to motivate actual engagement. The study discusses a number of specific challenges with regard to sharks which might be influencing the way in which society connects to shark related issues. It concludes with priority recommendations for further investigation into potential catalysts for public engagement in shark conservation.
\end{abstract}

Keywords: public engagement, public perception, shark conservation, shark fisheries 


\section{Introduction}

\subsection{The public as an actor for the marine environment}

As the impacts of human activities on the ocean and the potential consequences for human wellbeing become increasingly evident, there is a growing call for stronger public engagement in the governance of the marine environment [1-4]. The emerging concept of marine citizenship recognises each member of the public as a potential agent of change to address marine environmental issues through their behaviour choices $[5,6]$. Behaviour choices can include consumer decisions such as purchasing sustainably sourced seafood, or engagement with campaigning for policy change. Public support and engagement can be an important driver of environmental policies. The controversy surrounding whaling between whaling and non-whaling countries illustrates how public opinion can shape a country's position on the exploitation or protection of wildlife [7]. In Ireland, public support for a policy that in 2002 introduced a 15 Euro cent tax on plastic carrier bags achieved a significant change in behaviour. Since then, there has been a $90 \%$ reduction in the use of plastic bags [8]. It is not possible to predict how successful this policy would have been without public support, but the result of publicity and policy combined has been a public willing to make a significant behavioural change [9].

Public engagement in conservation and pro-environmental behaviour change is influenced by many variables [10]. There remain many uncertainties of how to catalyse marine citizenship; however, connectivity with the marine environment, an understanding of marine issues and pro-environmental values are likely to be key components $[5,6,9]$.

A well-informed public that understands an issue and its potential solutions is in a stronger position to exert pressure on policymakers to address environmental concerns [6]. Studies on public perceptions of marine wildlife have found that individuals with high levels of knowledge of and positive attitudes towards animals such as sharks or dolphins are more likely to support their conservation and avoid behaviour potentially harmful to these animals [11-13]. Attitudes and knowledge with regard to the marine environment and wildlife are shaped by several factors, including an individual's general interest, values and preconceptions, the physical and behavioural characteristics of an animal, formal educational exposure as well as 
socioeconomic and demographic variables [11-15]. Personal experience is another important influence on environmental attitudes and motivation for personal engagement and conservation behaviour $[16,17,18]$.

Despite being important elements of behaviour change, good knowledge and proenvironmental attitudes alone are often insufficient to encourage behavioural changes or active conservation engagement $[5,6,10]$. Previously, the 'knowledge deficit model' was accepted, which stated that behaviours could be changed by informing individuals of the negative impacts of their behaviours. Environmental behaviour models now recognise that behavioural choices are influenced by multiple factors, including internal variables such as values, attitudes and knowledge, and external factors such as infrastructure, policies and culture [10]. To successfully achieve behaviour change, a better understanding of how these factors influence public engagement with the particular issues must be gained.

Environmental knowledge, attitudes and values are known to vary throughout populations; the public is not homogenous in its perceptions of conservation issues $[9,19,20]$. This variation in the key factors influencing behaviour change is likely to lead to different responses to attempts to catalyse marine citizenship from different groups within the public [21]. This can lead to a differential uptake of new ideas across the population, with some groups adopting behaviour changes before others. This in itself can influence greater levels of behaviour changes as non-engaged groups are encouraged by those already performing the behaviour [20].

\subsection{The public and sharks}

With regard to sharks, public engagement and support for conservation is limited. The image of sharks as fearsome predators, cultural representation in movies such as Jaws and sensationalist media reports of shark attacks all contribute to frame sharks negatively in the public image $[11,13,22,23]$. Moreover, the physical and behavioural characteristics of most sharks, their predatory behaviour and the threatening image of their teeth, potentially influence attitudes towards them [14], even though three of the largest shark species are planctivorous and have no teeth at all. Personal experience with sharks could counteract the negative image of sharks $[16,17]$. A recent study on public perceptions of sharks in conjunction with shark bite incidents found that people living near shark frequented beaches hold high values of sharks and that these values do not appear to be negatively affected by shark bite 
accidents [24]. However, only a small minority of people is likely to encounter a shark in the wild. Negative preconceptions and inaccessibility of sharks to most of the public could be limiting public support for shark conservation. However, as mentioned above, the public is not uniform in its opinions and knowledge and therefore engagement with shark conservation may differ within the public audience.

\subsection{Shark ecology, fisheries and policies}

As top predators of the oceans, sharks play an integral role in the health and stability of marine ecosystems. However, they are particularly vulnerable to overexploitation as a consequence of their slow growth, late maturity, and low fecundity $[25,26]$. Over recent decades, commercial fisheries and other human activities have led to declining shark populations around the world [27-30]. The status of sharks in European seas is particularly critical with around half of all species being threatened with extinction or at risk of becoming endangered [31].

Since the mid-1980s, shark fisheries have increased considerably, driven by growing global fish consumption and declining catches in other fisheries [32,33]. Moreover, the rising demand for shark fins in East Asia's growing economies and the economic discrepancy between high value fins and low value meat have led to a dramatic expansion of the practice of finning $[31,33]$. Shark finning is defined as the removal of fins and discarding of the body at sea [34]. This is an inherently wasteful practice which contributes considerably to the depletion of sharks while hampering efforts to identify landed species and monitor populations [31,33]. Depletion of shark populations has potentially significant ecological and economic consequences $[26,35]$. In North Carolina, functional elimination of large sharks led to a proliferation of cownose rays which, in turn, reduced scallops to such low levels that the traditional local scallop fishery had to close [36].

Effective shark protection requires a coherent international strategy [37], changes in fisheries regulations worldwide, tailored conservation tools [38], improved data on shark ecology and species specific reporting of all catches [32,39]. However, despite growing recognition of their vulnerability and the potentially significant ecological and socioeconomic consequences of their depletion, sharks remain a low priority on the international conservation and management agenda [38,40]. Global shark catches are estimated to be three to five times higher than the official figures of the United Nations Food and Agriculture Organization due to lack of coherent reporting 
requirements $[38,41,42]$. No legally binding international agreement for shark conservation exists [39,40]. Implementation of the voluntary International Plan of Action for the Conservation and Management of Sharks by national governments, regional bodies and Regional Fisheries Management Organisations (RFMO) has been slow and ineffective $[39,43,44]$. Listings under international and regional fisheries agreements, conservation conventions and national legislation provide limited protection for only a small number of more charismatic shark species - such as basking shark, whale shark and great white shark [38-40,45,46]. Around the world, numerous Non-Government Organisations and organisations are working to raise public awareness and promote policies for improved shark conservation. However, their political influence is limited in the face of the considerable economic fisheries interests in sharks $[39,40,43]$.

The European Union (EU) is a major player in global shark fisheries. EU fleets, in particular Spain, Portugal, France and the United Kingdom (UK), account for the second largest share of global shark catches behind Indonesia $[33,47]$. The EU is the main supplier of shark products to Hong Kong and the largest importer of shark meat $[33,47]$. More stringent EU regulation of shark fisheries and stronger conservation policies has the potential to reduce the pressure on sharks in European seas and EU fishing grounds worldwide. Moreover the EU could use its considerable influence in the RMFOs to drive towards improved protection and a cessation of finning $[31,47]$. While it is uncertain whether stronger EU policies, such as the newly amended fining ban [48], would be adopted elsewhere, a strong EU stance on shark conservation and management could influence national governments, RFMOs and other regional bodies. The EU could thus take a leading role in the protection of sharks.

\subsection{Study aims}

This study investigated public perceptions of sharks and shark conservation. The sample population was those with an active interest in the marine environment and therefore those most likely to engage with shark conservation issues. The study assessed: a) respondent's knowledge of sharks and shark fisheries, b) respondent's attitudes towards sharks and opinions on shark conservation, and c) possible factors that influence respondent's knowledge and attitudes. The findings are used to make recommendations on how to create support for and enhance engagement in shark conservation. 


\section{Methods}

\subsection{Data collection}

Questionnaires were delivered face to face over a three week period in June and July 2011 at the National Marine Aquarium in Plymouth (121 respondents) and at the first Marine and Coastal Policy Forum hosted by the Centre for Marine and Coastal Policy Research at Plymouth University (14 respondents). A minimum sample size of 100 was determined as the number of respondents required for statistical validity and feasibility in the available time frame. The final total sample size was 135 . The venue selection was based on the assumption that aquarium visitors and marine conference attendees had expressed interest in the marine environment. This was the key criterion for the targeted survey population. Potential participants at both venues were approached in a friendly and discreet way and asked if they were happy to give a few minutes to answer a short survey. Only individuals eighteen years and over were interviewed, as stipulated by the ethical approval given by the Plymouth University Faculty of Science and Technology Research Ethics Committee. The survey was preceded by a pilot test and consequent amendments to the questionnaire.

The questionnaire encompassed six themes: 1) general knowledge of sharks, 2) knowledge of threats to sharks, 3) knowledge of shark fisheries and finning, 4) attitudes towards sharks and opinions on shark conservation, 5) connectedness to the marine environment (variables: regular aquarium visits, frequent coast visits, shark experience in the wild), and 6) standard socio-demographic variables. Anecdotal comments by the respondents were also recorded.

Three questions had optional follow-up questions that were only asked to respondents who answered the first question affirmatively. The question "Have you ever seen a shark in the wild?" was followed with questions examining the nature of the experience (64 respondents). Respondents who gave an answer between one and four to the question "On a scale of one (very threatened) to five (not threatened), to what extend do you think that sharks are under threat from human activities?" where further asked what they considered to be the greatest threat for sharks (133 respondents). Lastly, the question "Have you heard of shark finning?" led to further questions about finning (101 respondents). 


\subsection{Data analysis}

Frequencies of all responses were analysed to assess the profile of the study group. Cross tabulations were used to explore possible influencing factors. Significance of influences was tested with Pearson chi-square, with a critical $p$-value of 0.05 .

Quantitative questions included those with yes/no/don't know or true/false options and Likert type ratings. Qualitative open questions were coded after completion of the interviews to allow quantitative analysis of the responses. While Thompson and Mintzes [12] refer to Kellert's [49] typology of basic attitudes towards animals, in the present study a simpler positive/neutral/negative categorisation was chosen. This was considered to be more appropriate to the research objectives and the method of survey being delivered. Some of the comments made by the respondents were recorded as anecdotal evidence.

\section{Results}

\subsection{The study group}

Of the 135 respondents, $56 \%$ were female and $44 \%$ male. Respondents were evenly distributed across age groups ranging from 18 to 64 , whilst the over 65 age group was least represented with only nine respondents. Almost two thirds of respondents $(61 \%)$ had a university degree, postgraduate degree or equivalent professional qualification. Two thirds (68\%) lived less than 20 miles from the coast and about half (44\%) visited the coast daily or weekly. About $16 \%$ had a professional connection to marine or environmental concerns (science, conservation, other interactions), $23 \%$ were members of an environmental organisation and one third (37\%) visited marine aquariums on a regular basis. The marine and environmental bias of the profile points to a study group that is potentially engaged in marine issues.

\subsection{Knowledge and attitudes}

On average $93 \%$ of respondents answered the general knowledge questions about sharks correctly (Table 1). Almost all respondents knew that sharks are an important part of marine ecosystems (99\%) and that not all shark species are potentially threatening to humans $(97 \%)$. All but three knew that sharks exist in UK waters. A large majority was aware that global shark populations are declining $(98 \%)$ and that this is largely attributable to human activities (83\%). Of the 133 respondents asked 
what they considered to be the greatest threat to sharks, $70 \%$ selected commercial fishing, followed by habitat degradation (16\%). Over two thirds of all respondents either believed or strongly believed that sharks are being overexploited $(71 \%)$.

Table 1: Statements asked to assess knowledge of sharks and shark fisheries, preceded by the question "Can you please tell me whether you think the following statements are true or false?". A "don't know" option was not offered by the interviewer but was recorded if spontaneously given by the respondent. The table shows the percentages of "true", "false" and "don't know" responses given for each statement $(n=135)$. The correct responses are circled.

\begin{tabular}{|lccc|}
\hline & True \% & False \% & $\begin{array}{c}\text { Don't } \\
\text { know \% }\end{array}$ \\
\hline a) General knowledge of sharks: & & & \\
\hline Sharks are a type of fish & 80 & 18 & 2 \\
\hline All shark species are a potential threat to humans & 2 & 97 & 1 \\
\hline Sharks have to come to the surface to breath & 6 & 90 & 4 \\
\hline Sharks are an important part of marine ecosystems & 99 & 1 & 0 \\
\hline b) Shark fisheries knowledge: & & & \\
\hline Global shark populations are declining & 98 & 1 & 2 \\
\hline Sharks are not commercially fished in European seas & 21 & 59 & 20 \\
\hline $\begin{array}{l}\text { Sharks are caught accidentally when fishing for other } \\
\text { species }\end{array}$ & 93 & 4 & 3 \\
\hline Shark meat is consumed in the UK & 67 & 19 & 13 \\
\hline
\end{tabular}

Around two thirds of respondents (64\%) displayed positive attitudes towards sharks, expressing scientific and ecologic interest, aesthetic views, concern or fascination for sharks. Only $26 \%$ associated sharks with fear and danger (Table 2 ).

Regardless of personal attitudes towards sharks, a large majority morally rejected finning $(97 \%$ of $n=101)$ and catching sharks because of their alleged threat to humans $(94 \%$ of $n=135)$. Most respondents thought that sharks should be protected because of their ecological importance as well as a moral responsibility towards all species (95\%). An average $94 \%$ of those respondents that had previously expressed negative attitudes towards sharks supported these views. When asked whether EU regulations should provide protection for sharks, almost all respondents agreed (97\%), $76 \%$ of which strongly agreed. 
Table 2: Associations with sharks, given when asked to complete the sentence "I consider sharks to be...", categorised and divided into positive, neutral and negative attitudes towards sharks, and percentage distribution of responses $(n=135)$.

\begin{tabular}{|lc|}
\hline I consider sharks to be... & $\begin{array}{c}\text { Percentage } \\
\%\end{array}$ \\
\hline Positive & $\mathbf{6 4}$ \\
Fascinating, exciting, wonderful, charismatic, etc. & 18 \\
Interesting & 12 \\
Endangered & 10 \\
Essential part of the marine ecosystem, should be left alone in their & 8 \\
environment & \\
Beautiful & 4 \\
Efficient, important predators & 4 \\
Not dangerous, misunderstood & 4 \\
Two-sided: amazing, attractive yet wild, dangerous & 2 \\
We don't know enough about them & 2 \\
Should be protected & 1 \\
\hline Neutral & $\mathbf{1 0}$ \\
Animals, fish & 5 \\
Big & 5 \\
\hline Negative & $\mathbf{2 6}$ \\
Scary, dangerous, big teeth & 25 \\
Dull & 1 \\
\hline
\end{tabular}

Knowledge of shark fisheries and finning was lower than general knowledge of sharks. Little more than half of the respondents knew that sharks are commercially fished in European seas (59\%) and 20\% admitted that they did not know. Only 67\% of respondents thought that shark meat was consumed in the UK, and many of these mentioned in anecdotal comments that it is not common or associated it with the UK's Asian community. Overall, when asked about shark fisheries and finning, respondents gave more incorrect (average 17\%) and "don't know" (average 18\%) and fewer correct (average 66\%) answers than to the general knowledge questions (average 7\% incorrect, 2\% “don't know”, 91\% correct answers) (Figure 1, Table 1). Of the 101 respondents who had heard of shark finning only about half (53\%) gave an accurate explanation, including removal of fins and disposal of the body at sea, when asked what is meant by shark finning (Figure 2). 
a) General knowledge of sharks

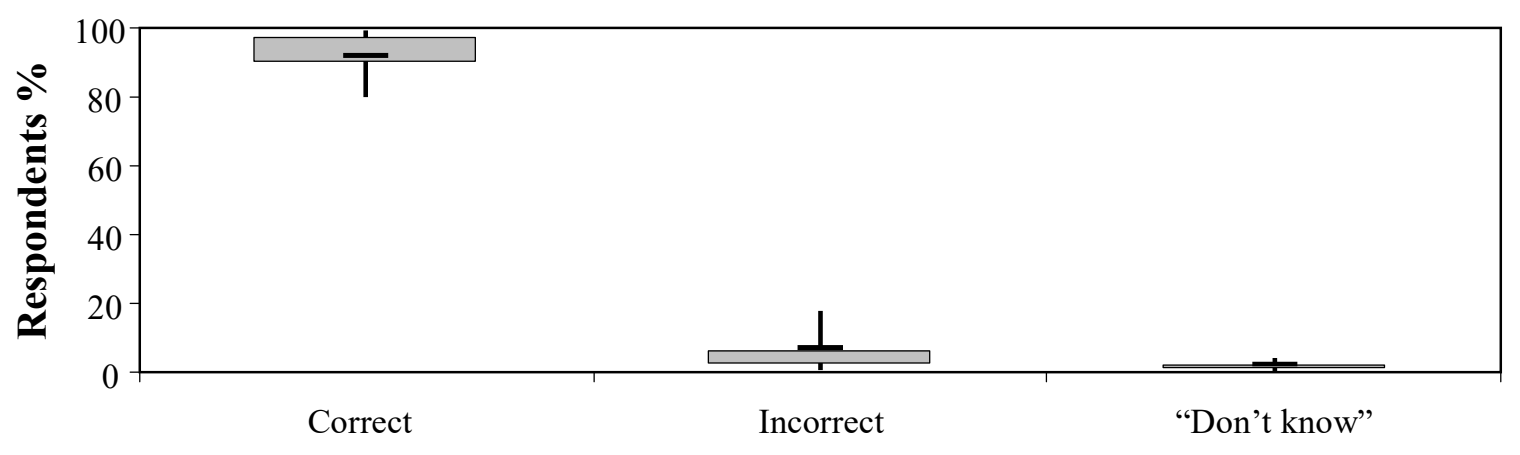

Responses

b) Shark fisheries knowledge

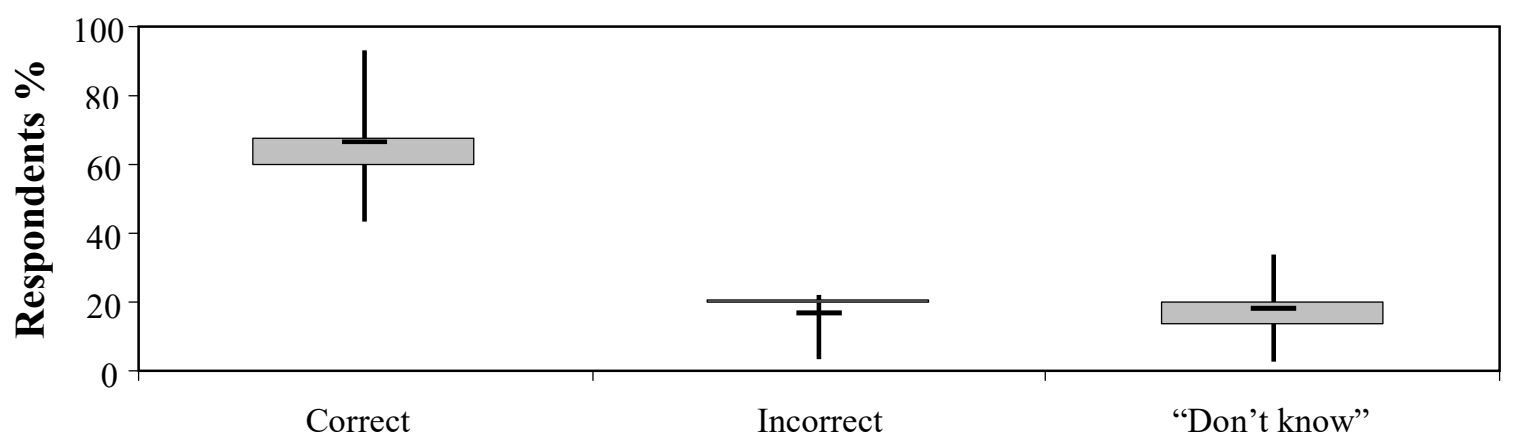

Responses

Figure 1: Comparison knowledge on sharks and shark fisheries, by comparing distribution of correct, incorrect and "don't know" responses for a) four questions on general knowledge of sharks and b) four questions on shark fisheries, $(n=135)$. The boxes and whiskers represent the distribution of percentages of respondents, the thick horizontal line represents the mean correct, incorrect or "don't know" responses. (See Table 1 for questions asked)

The question of whether sharks should be fished for economic profit proved controversial. The majority of respondents (86\%) disagreed with the exploitation of sharks solely for economic profit. However, recurring comments that ecologically sustainable fishing of sharks would be acceptable for the provision of food indicate that most respondents did not disagree with the idea of shark fishing in general. 


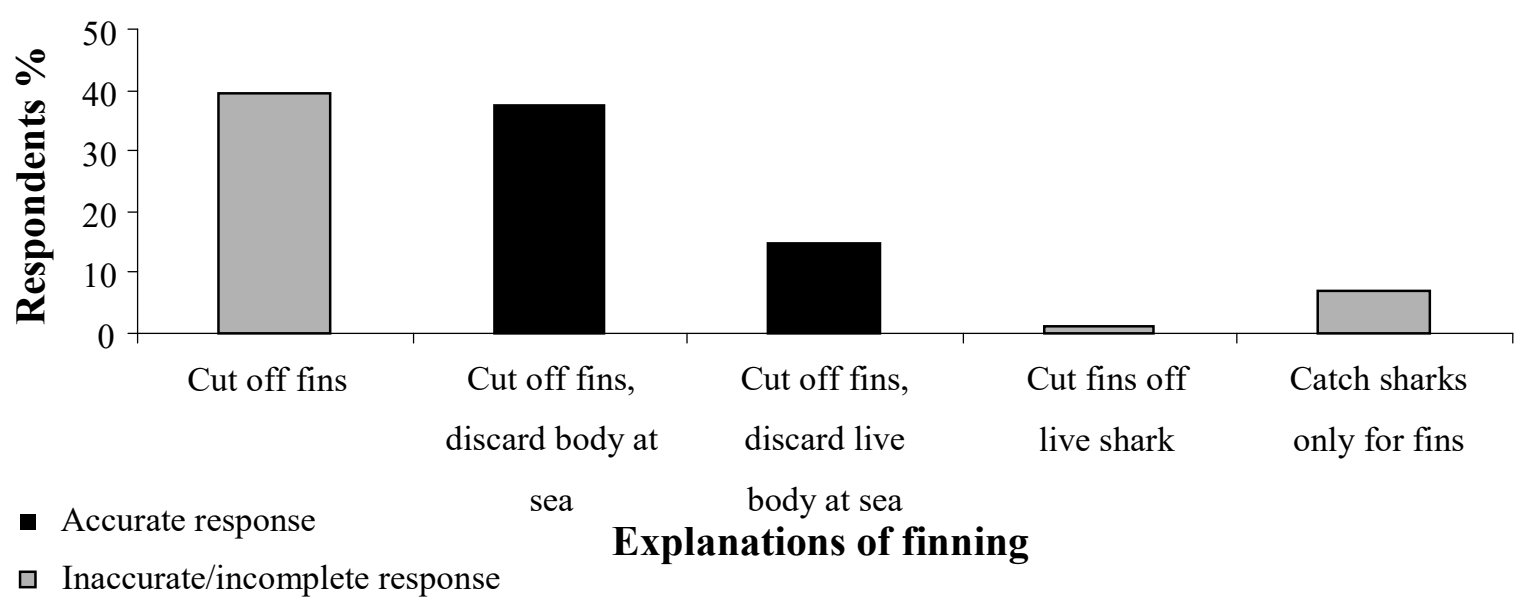

Figure 2: Knowledge on shark finning, explanations given in response to the question "Can you tell me what is meant by shark finning?" and percentage distribution of responses $(n=101)$.

When asked about the EU, most respondents did not think that the EU regulates shark fisheries ( $44 \%$ of $n=135)$ or finning $(47 \%$ of $n=101)$. About one third responded "don't know" (34\% and 28\% respectively). Anecdotal comments suggested a lack of trust in the effectiveness of EU regulations among the respondents who believed that the EU regulates shark fisheries and finning, despite an expressed feeling of general overregulation within the EU.

\subsection{Influence factors}

Respondent's experiences of sharks in the wild mainly included encounters while swimming, snorkelling or diving (25\%), sightings from boats $(28 \%)$ as well as sightings from beaches and coasts (20\%). Most encounters occurred in the UK (44\%), with the species involved likely being basking sharks. Other locations of encounters included the Caribbean (13\%), the Red Sea (5\%), Southern Africa (6\%), Australia (3\%) and the Maldives (3\%). Of the 64 respondents who had experienced a shark in the wild, only three described the encounter as negative. None of these three had negative feelings towards sharks and all three said that the encounter had no negative effect on their attitudes. The three negative encounters took place in the Caribbean and Australia. Of the ten respondents with negative attitudes towards sharks who had encountered a shark in the wild, none described the experience itself as negative. Overall, respondents with shark experience in the wild tended to have 
more positive and stronger pro-conservation attitudes than respondents with no shark experience.

With regard to other influencing factors on knowledge and attitudes it was found that respondents with a personal connection to sharks or the marine environment tended to have better knowledge of sharks, as well as awareness and understanding of the threats they face, than respondents with no such connection. Factors of personal connection included environmental organisation membership, regular aquarium visits and experience with sharks in the wild. Regular aquarium visitors and frequent coast visitors (daily or weekly) also tended to have more positive attitudes and stronger pro-conservation attitudes (Figure 3). For example, regular aquarium visits positively influenced attitudes towards sharks $\left(x^{2}=15.408, d f=2, p<0.001\right): 84 \%$ of regulars visitors had positive attitudes towards sharks compared to $52 \%$ of non-regulars.

\section{a) Aquarium visits}

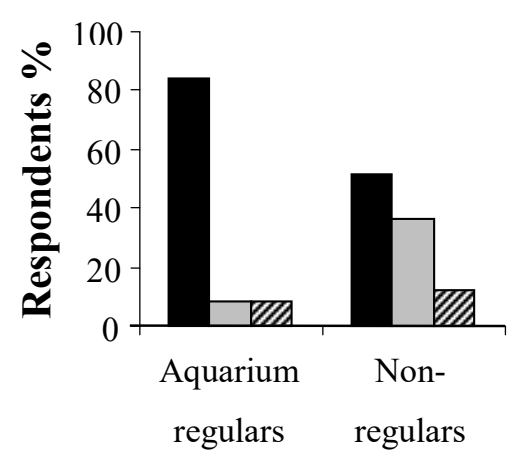

Influencing factors b) Coast visits

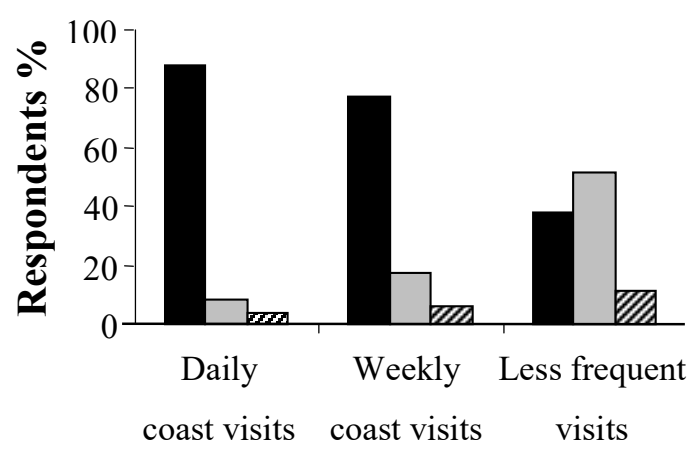

Influencing factors

- Positive $\square$ Negative $\square$ Neutral

Figure 3: Attitudes towards sharks of respondents with experience and personal connection to sharks or the marine environment and with no such connection (a) regular and non-regular aquarium visitors, b) daily, weekly and less frequent coast visitors) $(n=135)$.

No recognisable trend or significant influence on knowledge of or attitudes towards sharks was found for the other tested influence factors. This can be explained by the profile of the study group, i.e. the even distribution across gender, age groups and levels of education and the bias towards coastal locations of residence, as well as the generally high levels of knowledge and positive attitudes across the group. 


\section{Discussion}

The respondents in this study, who had shown an interest in the marine environment by visiting the marine aquarium or conference, demonstrated good knowledge, proconservation values and positive attitudes with regard to sharks. Respondents had a good general knowledge of sharks as well as awareness and understanding of the threats they face. Respondents had predominantly positive attitudes towards sharks and a strong belief that sharks should be protected. These are factors considered to be important for engagement with environmental issues [5,9-12,49]. The sampled group represents members of the public who are well informed, interested and likely to be already engaged with the marine environment. Though not representative of the UK public, this group may be more likely to engage with marine conservation issues and has the potential to drive change in conservation policy.

The respondents had overwhelmingly positive opinions of sharks, considering them to be fascinating, interesting, beautiful and misunderstood (Table 2). This finding rejects to a large extent the idea that the public image of sharks is that of 'man eating monsters'. The respondents recognised the predatory nature of sharks, but the most frequent responses suggest an element of awe and wonder rather than fear and disgust. This indicates that Jaws-like preconceptions are not a barrier to engagement for the study group. Instead, interest and fascination could be a good foundation to engage this group more proactively in shark conservation.

The study points to a number of factors that relate to how this group has gained the high level of knowledge and positive attitudes. Media coverage of shark fisheries just prior to the study was quite high in the UK, where this study was conducted. The film Sharkwater, Channel Four's Fish Fight series and Shark bait (which accompanied the 'Big Fish Fight', a campaign by UK based NGOs) had given a relatively high profile to sharks from a conservation perspective, rather than the traditional sensational negative representation of sharks in the media. This type of coverage may be contributing to a widespread increase in public interest in shark conservation. In the present study, the questions on shark bycatch and finning, two highly featured topics in the above mentioned programmes, generated considerably higher percentages of correct responses compared to the other fisheries questions, suggesting that these programmes might have increased public awareness of the issues. However, due to absence of research into the impacts of these programmes, 
it is not possible to determine to what extent these programmes might have contributed to public awareness and engagement.

The results also show that respondents who are members of Environmental NonGovernment Organisations (ENGOs) and who visit aquariums on a regular basis had the highest knowledge of sharks and shark related issues. This echoes findings in previous studies where generic engagement with the marine environment is correlated with increased knowledge of specific elements of this environment [21].

Direct experience has been recognised as an important variable for developing proenvironmental values $[17,18,24]$. The shark encounters described here illustrate positive experiences, and the small number of negative experiences did not negatively impact on the individual's attitudes towards shark conservation. Respondents who had encountered a shark in the wild displayed more positive and stronger pro-conservation attitudes towards sharks. This first hand experience rejects the typical portrayal of sharks as scary man eating creatures and suggests that a more positive representation may be possible. The National Marine Aquarium in Plymouth is home to many shark species, with the large nurse sharks and sandtiger sharks being a particular attraction. The scale to which an aquarium can replicate a wild encounter is not known, however there is a real potential that the ability to get very close to sharks in an aquarium may also have an impact on visitor perceptions of sharks. The Monterey Bay Aquarium in California is exhibiting young white sharks to change people's attitudes and promote shark conservation as part of their 'Project White Shark'. According to the Aquarium, these white sharks are "the most powerful emissar[ies] for ocean conservation" they have ever had [50]. The present study confirms the important role that aquaria could play in capturing and enhancing potential support for shark conservation.

Many variables are recognised as influencing public engagement with environmental issues; knowledge, attitudes and values are key in this. The findings recorded here suggest that this engaged group of the public have the necessary knowledge, attitudes and values which may be considered necessary to support an agenda for strong shark conservation. However, no public outcry is heard over the current activity of shark fisheries and no policy or governance response is demanded by society to address the global decline of shark populations. Public engagement is recognised to be a complex process, which is further supported by the findings of this 
study. In particular, the existence of a knowledge-action gap has been widely acknowledged: individuals require more than knowledge of an issue to catalyse a behavioural response [10]. Despite the apparent addition of positive attitudes and values towards shark conservation, there is still no evidence of wider society engaging with shark conservation issues. Research into public engagement with conservation issues and associated behaviour changes has identified the complexities of this relationship. At a generic level, it is possible to identify variables which appear to be important to establishing this relationship [10]. However, the present findings indicate that the specific nature of shark issues may also be a strong influence on the way in which society connects with an issue and could explain the lack of public outcry.

The finding that most respondents did not disagree in principle with shark fisheries indicates a lack of understanding of the ecology of sharks, their particular vulnerability to overexploitation and the related difficulties of maintaining shark fisheries sustainable. Although it is recognised that knowledge is not the only variable involved in behaviour change, some types of knowledge around an issue can be essential for engagement $[5,6,13]$. Therefore, the knowledge gaps recorded in this study may be limiting active engagement in shark conservation.

In terms of knowledge, respondents knew least about issues around shark fisheries. Fisheries are a major threat to shark populations. The low scores of correct responses and high degree of uncertainty for the questions on commercial shark fisheries in the EU and shark consumption in the UK as well as frequent anecdotal comments on Asian markets suggest that shark fisheries may be perceived as a distant issue with no implications for the UK. However, if a problem is perceived as not being relevant to UK audiences, this in itself is not necessarily a barrier to engagement. For example, the UK public engaged strongly with the controversy around whaling, an issue which occurs in oceans around the world but not in UK seas.

There is much evidence from other fields of study, such as energy use or waste disposal, which have informed the wider understanding of behaviour change (e.g. [10]). Although this background provides useful guidance for engaging society with an issue, it is essential to understand the specificities of the particular issue and how this may influence potential engagement. In the case of shark conservation, there are 
a number of challenges which we consider may strongly influence society's connection with the issue; these need further investigation as to what extent they are barriers to engagement and how they can be overcome.

- Sharks are a very specific topic. Anecdotal comments given by respondents in this study indicate that even among those interested in the marine environment, sharks are "not [necessarily] high on the personal radar" (respondent's comment).

- The issue of shark conservation relates to many different species, a multitude of seas and various human activities. It is a disparate issue, indeed, a suite of many issues under one umbrella issue - the need for better protection of sharks. This increases the challenge of connecting audiences with shark depletion.

- As suggested above, the UK public might perceive issues surrounding sharks as being disconnected from the UK, both in terms of consumer activities, impacts on sharks and implications of shark depletion.

- Related to disconnectedness, there is a lack of clear behaviour responses which individuals may take to support shark conservation. The issues surrounding sharks are so complex that a number of societal responses are likely to be required, including demanding policy reforms and purchase choices that avoid shark products and products from species which indirectly impact shark populations e.g. through bycatch. These behaviours may all require a different set of behavioural triggers.

- The lack of scientific understanding of the pathways of impact between societal activities and the extent to which these drive the decline of shark populations make it difficult to highlight the priority behaviours to progress the shark conservation agenda.

Identifying the behaviour changes which could have the greatest conservation benefit to sharks should be a priority research theme. Many individuals have no direct contact with shark products and so are not clear about actions to take. Guidance for engaging society with shark conservation is currently missing, and as a result, it is difficult to see a clear direction to focus engagement activities. These activities may include product labelling, programmes to disseminate information on products that have a direct or indirect impact on sharks to consumers, or enabling consumers to make informed decisions in restaurants, such as identifying 'shark-free' restaurants, where no shark products are served. Activities might also include guidelines for 
anglers on good catch-and-release practice and recording of their catch. These priorities may differ between countries, depending on the types of societal activities which drive the pressures on shark populations.

In addition to encouraging behaviour changes that would benefit sharks, ways also need to be found to connect people with sharks, to make shark depletion relevant, so as to raise societal pressure on policy makers and regulators, similar to the antiwhaling movement. This study suggests that the personal experience with sharks offered by marine aquaria could be a potential entry point for capturing people's attention for sharks.

\section{Conclusions}

The issues of shark conservation are multiple and complex. Study results illustrate that there are groups among the UK public that display the key prerequisites for engagement in shark conservation: they are interested, knowledgeable and have pro-conservation attitudes. These groups do not share the negative preconceptions of sharks as ferocious man eaters that still prevail in the public image of sharks and might be limiting support among the broader public. Personal experience with sharks, general marine interest and media coverage of shark issues appear to be important factors shaping these groups' images of sharks. However, knowledge, interest and support are not enough to motivate active engagement in shark conservation. To a certain extent, this may illustrate a gap between knowledge and action in which other factors are preventing behaviour change. We have discussed a number of specific challenges related to sharks and their conservation which might be influencing the way in which society connects to these issues. These range from the diversity of shark species, threats and conservation needs to the lack of clear public behaviour choices. Further investigation is required to identify catalysts for public engagement in shark conservation, but we suggest two priorities for the next steps:

- Investigating whether the disconnect between the UK public and shark conservation prevents public engagement with shark protection priorities;

- Identification of clear behaviours required to support shark conservation. 


\section{Acknowledgements}

We would like to thank the National Marine Aquarium in Plymouth for providing the venue for this study. We would also like to thank all the aquarium visitors and attendants of the MarCoPol Forum who took the time to answer to our questions. The study was conducted as part of a Master's thesis at Plymouth University.

\section{References}

[1] Lotze HK, Coll M, Magera AM, Ward-Paige C, Airoldi L. Recovery of marine animal populations and ecosystems. Trends in Ecology and Evolution 2011; 26 : 595-605.

[2] Rogers AD, Laffoley D. International Earth system expert workshop on ocean stresses and impacts. Summary report. Oxford: IPSO; 2011.

[3] Vincent ACJ. Saving the shallows: focusing marine conservation where people might care. Aquatic Conservation: Marine and Freshwater Ecosystems 2011; 21: 495-499.

[4] Fletcher S, Jefferson R, McKinley E. Exploring the shallows: a response to 'Saving the shallows: focusing marine conservation where people might care'. Aquatic Conservation: Marine and Freshwater Ecosystems 2012; 22(1): 7-10.

[5] Fletcher S, Potts J. Ocean citizenship: An emergent geographical concept. Coastal Management 2007; 35: 511-524.

[6] McKinley E, Fletcher S. Individual responsibility for the oceans? An evaluation of marine citizenship by UK marine practitioners. Ocean and Coastal Management 2010; 53: 379-384.

[7] Hamzaki T, Tanno D. Approval of whaling and whaling-related beliefs: public opinion in whaling and nonwhaling countries. Human Dimensions of Wildlife 2001; 6(2): 131-144.

[8] Convery F, McDonnell S, Ferreira S. The most popular tax in Europe? Lessons from the Irish plastic bags levy. Environmental and Resource Economics 2007; 38(1): 1-11.

[9] Jefferson R. Communicating marine environmental health; connecting science, social and policy values. PhD thesis, University of Plymouth, UK; 2010.

[10] Kollmuss A, Agyeman J. Mind the Gap: why do people act environmentally and what are the barriers to pro-environmental behaviour? Environmental Education Research 2002; 8(3): 239-260. 
[11] Thompson TL, Mintzes JJ. Cognitive structure and the affective domain: on knowing and feeling in biology. International Journal of Science Education 2002; 24(6): 645-660.

[12] Barney EC, Mintzes JJ, Yen CF. Assessing knowledge, attitudes, and behavior toward charismatic megafauna: the case of dolphins. Journal of Environmental Education 2005; 36(2): 41-55.

[13] O'Bryhim J. Public Knowledge, Attitudes, and Behavior towards Sharks and Shark Conservation. Master thesis, George Mason University, Washington D.C., USA; 2009.

[14] Kellert SR, Black M, Rush CR, Bath AJ. Human culture and large carnivore conservation in North America. Conservation Biology 1996; 10(4): 977-990.

[15] Steel BS, Smith C, Opsommer L, Curiel S, Warner-Steel R. Public ocean literacy in the United States. Ocean and Coastal Management 2005; 48: 97114.

[16] Rajecki DW. Attitudes, themes and advances. Second edition. Sunderland (MA), USA: Sinauer Associates, Inc.; 1990.

[17] Miller JR. Biodiversity conservation and the extinction of experience. Trends in Ecology and Evolution 2005; 20(8): 430-434.

[18] Bögeholz S. Nature experience and its importance for environmental knowledge, values and action: recent German empirical contributions. Environmental Education Research 2006; 12(1): 65-84.

[19] Schultz P W, Zelezny L. Reframing environmental messages to be congruent with American values. Human Ecology Review 2003; 10(2): 126-136.

[20] Defra. A framework for pro-environmental behaviours. Technical Report, Department for Environment, Food and Rural Affairs, UK; 2008.

[21] Jefferson RL, Bailey I, Laffoley D, Richards JP, Attrill MJ. Public perceptions of the UK marine environment. Marine Policy 2014; 43: 327-337.

[22] Morey S. The Shark in Modern Culture: Beauty and the Beast. Journal of Undergraduate Research 2002; 4.

[23] Dobson J. Jaws or Jawesome? Exploring the shark-diving experience. In: Lück M, Graeupl A, Auyong J, Miller ML, Orams MB (eds). Proceedings of the 5th International Coastal and Marine Tourism Congress: Balancing Marine Tourism, Development and Sustainability. New Zealand Tourism Research Institute, AUT University, Auckland, New Zealand; 2007: pp. 37-49. Cited from: O’Bryhim J. Public knowledge, attitudes, and behavior towards sharks and shark conservation. Master thesis, George Mason University, Washington D.C., USA; 2009. 
[24] Neff CL, Yang JYH. Shark bites and public attitudes: policy implications from the first before and after shark bite survey. Marine Policy 2013; 38: 545-547.

[25] Cailliet G, Musick JA, Simpfendorfer CA, Stevens JD. Ecology and life history characteristics of chondrichthyan fish. In: Fowler SL, Cavanagh RD, Camhi M, Burgess GH, Cailliet GM, Fordham SV, Simpfendorfer CA, Musick JA (eds). Sharks, rays and chimaeras: the status of the chondrichthyan fishes. Status Survey. IUCN/SSC Shark Specialist Group, Gland, Switzerland and Cambridge, UK; 2005: 12-18.

[26] Stevens JD, Bonfil R, Dulvy NK, Walker PA. The effects of fishing on sharks, rays, and chimaeras (chondrichthyans), and the implications for marine ecosystems. ICES Journal of Marine Science 2000; 57: 476-494.

[27] Rogers SI, Ellis JR. Changes in the demersal fish assemblages of British coastal waters during the 20th century. ICES Journal of Marine Science 2000; 57: 866-881.

[28] Baum JK, Myers RA, Kehler DG, Worm B, Harley SJ, Doherty PA. Collapse and conservation of shark populations in the Northwest Atlantic. Science 2003; 299: 389-392.

[29] Baum JK, Myers RA. Shifting baselines and the decline of pelagic sharks in the Gulf of Mexico. Ecology Letters 2004; 7: 135-145.

[30] Ellis JR, Dulvy NK, Jennings S, Parker-Humphreys M, Rogers SI. Assessing the status of demersal elasmobranchs in UK waters: a review. Journal of the Marine Biological Association of the UK 2005; 85: 1025-104.

[31] Fordham S. Shark Alert. Revealing Europe's impact on shark populations. The Shark Alliance; 2006.

[32] Musick JA. Introduction. In: Fowler SL, Cavanagh RD, Camhi M, Burgess GH, Cailliet GM, Fordham SV, Simpfendorfer CA, Musick JA (eds). Sharks, rays and chimaeras: the status of the chondrichthyan fishes. Status Survey. IUCN/SSC Shark Specialist Group, Gland, Switzerland and Cambridge, UK; 2005: pp. 111.

[33] Hareide NR, Carlson J, Clarke M, Clarke S, Ellis J, Fordham S, Fowler S, Pinho M, Raymakers C, Serena F, Séret B, Polti S. European Shark Fisheries: a preliminary investigation into fisheries, conversion factors, trade products, markets and management measures. European Elasmobranch Association; 2007.

[34] Fowler SL, Cavanagh RD, Camhi M, Burgess GH, Cailliet GM, Fordham SV, Simpfendorfer CA, Musick JA (eds). Sharks, rays and chimaeras: the status of the chondrichthyan fishes. Status Survey. IUCN/SSC Shark Specialist Group. Gland, Switzerland and Cambridge, UK; 2005. 
[35] Heithaus MR, Frid A, Wirsing AJ, Worm B. Predicting ecological consequences of marine top predator declines. Trends in Ecology and Evolution 2008; 23(4): 202-210.

[36] Myers RA, Baum JK, Shepherd TD, Powers SP, Peterson CH. Cascading Effects of the Loss of Apex Predatory Sharks from a Coastal Ocean. Science 2007; 315: 1846-1850.

[37] Herndon A, Gallucci VF, DeMaster D, Burke W. The case for an international commission for the conservation and management of sharks (ICCMS). Marine Policy 2010; 34: 1239-1248.

[38] Dulvy NK, Baum JK, Clarke S, Compagno LJV, Cortés E, Domingo A, Fordham S, Fowler S, Francis MP, Gibson C, Martínez J, Musick JA, Soldo A, Stevens J, Valenti S. You can swim but you can't hide: the global status and conservation of oceanic pelagic sharks and rays. Aquatic Conservation: Marine and Freshwater Ecosystems 2008; 18: 459-482.

[39] Techera EJ, Klein N. Fragmented governance: Reconciling legal strategies for shark conservation and management. Marine Policy 2011; 35: 73-78.

[40] Jacques PJ. The social oceanography of top oceanic predators and the decline of sharks: A call for a new field. Progress in Oceanography 2010; 86: 192-203.

[41] Clarke S, McAllister MK, Milner-Gulland EJ, Kirkwood GP, Michielsens CGJ, Agnew DJ, Pikitch EK, Nakano H, Shivji MS. Global estimates of shark catches using trade records from commercial markets. Ecology Letters 2006; 9: 11151126.

[42] Worm B, Davis B, Kettemer L, Ward-Paige CA, Chapman D, Heithaus MR, Kessel ST, Gruber SH. Global catches, exploitation rates, and rebuilding options for sharks. Marine Policy 2013; 40: 194-204.

[43] Fowler SL, Cavanagh RD. International conservation and management initiatives for chondrichthyan fish. In: Fowler SL, Cavanagh RD, Camhi M, Burgess GH, Cailliet GM, Fordham SV, Simpfendorfer CA, Musick JA (eds). Sharks, rays and chimaeras: the status of the chondrichthyan fishes. Status Survey. IUCN/SSC Shark Specialist Group, Gland, Switzerland and Cambridge, UK; 2005: pp. 58-69.

[44] Lack M, Sant G. The Future of Sharks: A Review of Action and Inaction. TRAFFIC International and the Pew Environment Group; 2011.

[45] Núñez GNE. Sharks: Conservation, Fishing and International Trade. Bilingual edition. Dirección General para la Biodiversidad. Ministerio de Medio Ambiente, y Medio Rural y Marino, Madrid, Spain; 2008.

[46] Defra. Shark, Skate and Ray Conservation Plan. Department for Environment, Food and Rural Affairs, UK; 2011. 
[47] Fowler S, Séret B. Shark fins in Europe: Implications for reforming the EU finning ban. European Elasmobranch Association and IUCN Shark Specialist Group; 2010.

[48] EC. Shark finning. The European Parliament has overwhelmingly voted to strengthen a previous Council Regulation which has banned shark finning since 2003. European Commission online press release 23.11.2012.

[49] Kellert SR. Public perceptions of predators, particularly the wolf and coyote. Biological Conservation 1985; 31: 167-189.

[50] Monterey Bay Aquarium. Monterey Bay Aquarium Project White Shark. Saving White Sharks; 2011. http://www.montereybayaquarium.org/cr/whiteshark.aspx [accessed 07.09.2011]. 